\section{Archives of Allergy \\ and Immunology}

Int Arch Allergy Immunol 2020;181:563-564

DOI: $10.1159 / 000508750$
Received: May 18, 2020

Accepted: May 18, 2020

Published online: May 26, 2020

\title{
JAK Inhibition with Methotrexate as Treatment for COVID-19 Is a Double-Edged Sword
}

\author{
Sujoy Khan ${ }^{\text {a }}$ Senthil Durairaj ${ }^{b}$ \\ ${ }^{a}$ Department of Immunology and Allergy, Hull University Teaching Hospitals NHS Trust, Queen's Center, Castle Hill \\ Hospital, Cottingham, UK; ${ }^{b}$ Department of Hematology and Hemato-Oncology, Hull University Teaching Hospitals \\ NHS Trust, Queen's Center, Castle Hill Hospital, Cottingham, UK
}

Dear Editor,

The review article by Farhad Seif et al. [1] on JAK inhibition as a treatment strategy for COVID-19 is a plausible option given that it would certainly block effects of severe inflammatory cytokines including IL-13 (responsible for airway reactivity and mucus secretion) [2]. Our concern is whether methotrexate (MTX) addition is feasible given that (1) oral MTX takes several weeks to build up effect; and (2) intravenous MTX dose adjusted to the body surface area may be an intermediate dose or high dose at $1.5 \mathrm{~g} / \mathrm{m}^{2}$ or $3-8 \mathrm{~g} / \mathrm{m}^{2}$, respectively [3]. On an ethical consideration, the parenteral route could only be justified if there were central nervous system complications of COVID-19. If JAK inhibition was considered for 7-14 days, a single intravenous dose of MTX is the most likely option. Even then, managing patients with severe mucositis (who are ventilated), hydration (when euvolemia is the target in severe COVID-19 and aggressive hydration is recommended after high-dose MTX) and leukovorin (folinic acid) rescue may prove to be exceedingly clinically challenging in a patient who is already struggling to control a hyper-inflammatory immune response to a novel virus.

Natural killer function is also dependent on cytokines via the JAK-STAT pathway and functional exhaustion of

karger@karger.com

(c) 2020 S. Karger AG, Basel

www.karger.com/iaa

Karger these cells is a feature in severe COVID-19 infection [4]. Seif and colleagues mention that JAK inhibitors can target both type I (IFN- $\alpha /$ IFN- $\beta$ ) and type II interferons (IFN- $\gamma$ ) but it is also important to remember that interferons are major cytokines involved in viral clearance [5]. The current recommendations from the British Society of Hematology therefore state that patients who are on ruxolitinib (non-selective JAK inihibitor) for myeloproliferative neoplasms have a weakened immune system and are therefore likely to be at increased risk of COVID- 19 infection [6].

It is worthwhile to note that patients on anti-cytokine biological immunomodulatory drugs do not seem to be more vulnerable than originally presumed as evidenced by reports from Gisondi et al. [7] from Northern Italy and Haberman et al. [8] from New York. An observational study of IL-1 blockade in COVID-19 showed that patient survival at 21 days was $90 \%$ in the high-dose anakinra group as compared to $56 \%$ in the standard treatment group $(p=0.009)$. Mechanical ventilation-free survival was $72 \%(21 / 29)$ in the anakinra group versus $50 \%(8 / 16)$ in the standard treatment group $(p=0.15)$ [9]. Another

Edited by: H.-U. Simon, Bern. 
report on 8 patients with severe COVID-19 and hemophagocytic lymphohistiocytosis suggested IL-1 blockade with anakinra as a beneficial treatment option [10]. The side effects of IL-1 blockade are much more manageable than parenteral MTX in the acute setting, and we therefore think that selective JAK inhibition with IL-1 and/or IL-6 blockade in patients with severe COVID-19 infection have more merit to be considered in future clinical trials from the perspectives of patient safety and tolerability.

\section{Disclosure Statement}

The authors have no conflicts of interest to declare.

\section{Funding Sources}

The authors received no funding for this article.

\section{Author Contributions}

S.K., S.D. - Substantial contributions to the conception or design of the work.

S.K., S.D. - Drafting the work or revising it critically for important intellectual content.

S.K., S.D. - Final approval of the version to be published.

S.K., S.D. - Agreement to be accountable for all aspects of the work in ensuring that questions related to the accuracy or integrity of any part of the work are appropriately investigated and resolved.

\section{References}

1 Seif F, Aazami H, Khoshmirsafa M, Kamali M, Mohsenzadegan M, Pornour M, et al. JAK inhibition as a new treatment strategy for patients with COVID-19. Int Arch Allergy Immunol. 2020 May 11;1-9.

2 Schwartz DM, Kanno Y, Villarino A, Ward M, Gadina M, O'Shea JJ. JAK inhibition as a therapeutic strategy for immune and inflammatory diseases. Nat Rev Drug Discov. 2017 Dec;17(1):78.

3 Rubenstein JL, Gupta NK, Mannis GN, Lamarre AK, Treseler P. How I treat CNS lymphomas. Blood. 2013 Oct;122(14):2318-30.

4 Zheng M, Gao Y, Wang G, Song G, Liu S, Sun $D$, et al. Functional exhaustion of antiviral lymphocytes in COVID-19 patients. Cell Mol Immunol. 2020 May;17(5):533-5.
5 British Society for Hematology. Myeloproliferative neoplasms advice [accessed 13 May 2020]. Available from: https://b-s-h.org.uk/ about-us/news/covid-19-updates/.

6 Schett G, Sticherling M, Neurath MF. COVID-19: risk for cytokine targeting in chronic inflammatory diseases? Nat Rev Immunol. 2020 May;20(5):271-2.

7 Gisondi P, Facheris P, Dapavo P, Piaserico S, Conti A, Naldi L, et al. The impact of COVID-19 pandemic on patients with chronic plaque psoriasis being treated with biologic therapy: the Northern Italy experience. Br J Dermatol. 2020. DOI: 10.1111/bjd.19158.

8 Haberman R, Axelrad J, Chen A, Castillo R, Yan D, Izmirly P, et al. Covid-19 in ImmuneMediated Inflammatory Diseases - Case Series from New York. N Engl J Med. 2020. DOI: 10.1056/NEJMc2009567.
9 Cavalli G, De Luca G, Campochiaro C, DellaTorre E, Ripa M, Canetti D, et al. Interleukin-1 blockade with high-dose anakinra in patients with COVID-19, acute respiratory distress syndrome, and hyperinflammation: a retrospective cohort study. Lancet Rheumatol. 2020 May 7. DOI: 10.1016/S26659913(20)30127-2.

10 Dimopoulos G, de Mast Q, Markou N, Theodorakopoulou M, Komnos A, Mouktaroudi $\mathrm{M}$, et al. Favorable anakinra responses in severe COVID-19 patients with secondary hemophagocytic lymphohistiocytosis. Cell Host Microbe. 2020 May. DOI: 10.1016/j. chom.2020.05.007. 